\title{
OBRA-AULA: prática e poética do banal de uma artistagem docente
}

\author{
Thiago Heinemann Rodeghiero \\ Carla Gonçalves Rodrigues
}

\section{Resumo}

Este artigo trata da contribuição que a arte contemporânea vem a oferecer à prática docente e é justificado pela relevância de pensar a criação de uma aula que não dependa de modelos. Objetiva evidenciar a poética artística do pesquisador e sua relação com a artistagem docente de Corazza. Mostrando os encontros e experimentações entre arte e filosofia, vaza na educação. Desenha-se num plano de consistência nas margens filosóficas, artísticas e educacionais. Nas Filosofias da Diferença de Deleuze e Guattari, encontra vetores que colocam os significados hegemônicos a se transformar. Partindo desse esboço, constrói um agenciamento que mostra desterritorializações entre as relações estabelecidas. Busca referências na produção do fazer junto de Kaprow, nas sensações de Malevich e na zona invisível de Duchamp, uma orientação para modular com a prática artística do pesquisador. Logo, desenha-se num método que se monta fazendo. Um passarinhar à maneira de uma cartografia que voa por um território, encontrando forças.

Palavras-chave: educação; arte; filosofias da diferença; cartografia; artistagem

WORKING-ART: banal poetic and practice of a teaching-acting in teaching

\begin{abstract}
This research deals with the contribution that contemporary art can make to teaching practice and is justified by the relevance of thinking about the creation of a class that does not depend models. It aims to evidence a Class-Artwork through the artistic production of the researcher and its relation with the acting of Corazza. Perceives the leaks that contemporary art brings to education, he shows the encounters and experiments with these areas. It outlines a plan of consistency on the blurred frontiers of philosophy, art, and education. In the Philosophies of Difference of Deleuze and Guattari, they find power to manifest the transformations of hegemonic meanings embedded in signifiers and signified. Starting from this design, an Assemblage is set up that shows deterritorializations between established relations. He looks for art references in making with of Kaprow, in the sensations of Malevich and in the invisible zone of Duchamp, orientation for the artistic practice of the researcher. Thus, one draws on a method that is assembled by doing. A to Bird in the manner of a cartography that flies through a territory, finding strength.
\end{abstract}

Keywords: education; art; philosophies of difference; cartography; teaching-acting

OBRA-CLASE: práctica y poética de lo banal de un artistagem docente

Resumen

Este artículo aborda el aporte que el arte contemporáneo ofrece a la práctica docente y se justifica por la relevancia de pensar en crear una clase que no dependa de modelos. Tiene como objetivo resaltar la poética artística de la investigadora y su relación con la artistagem docente de Corazza. Mostrando los encuentros y experimentos entre el arte y la filosofía, la educación filtra un pensamiento sobre ella como una artistagem. Está diseñado sobre un plan de consistencia en los márgenes filosófico, artístico y educativo. En las Filosofías de la diferencia de Deleuze y Guattari, encuentran vectores que sitúan significados hegemónicos a transformar. A partir de este esquema, construye una agencia que muestra desterritorializaciones entre las 
relaciones establecidas. Busca referencias en la producción del hacer junto a Kaprow, en las sensaciones de Malevich y en la zona invisible de Duchamp, una orientación para modular con la práctica artística del investigador. Por lo tanto, está diseñado en un método que se ensambla haciendo. Un paseo a la manera de la cartografía que vuela por un territorio, encontrando fuerzas.

Palabras clave: educación; arte; filosofías de la diferencia; cartografía; artistagem

\title{
INTRODUÇÃO
}

\author{
É preciso que algo force o pensamento, abale-o e o arraste \\ numa busca; em vez de uma disposição natural, bá uma \\ incitaşão fortuita, contingente, que depende de um encontro. \\ (ZOURABICHVILI, 2016, p. 51, grifo do autor).
}

Este artigo seleciona um recorte da produção artística do pesquisador a fim de evidenciar uma Obra-Aula, agenciando com os artistas referência, artistagem docente (CORAZZA, 2011, 2013) com os processos, procedimentos e criações de uma poética. Protegendo-se do caos, é escolhida uma série que compõe a Poética do Banal: Ob.soles.cên.ci.a de 2017.

Os trabalhos aqui expostos são tensionados a pensar como processo de uma prática docente-artista. Os elementos que compõe este território de pensamento compõem um plano não dogmático. Compostas de fotografias, vídeos, desenhos e anotações, as obras do artista deixam emergir a pungência que alicerça os seus fazeres. Elas têm algo em comum: um artista-pesquisador que se ocupa em operar espaços e objetos residuais; sua rotina de trabalho; e o descarte/desuso.

O banal é uma transformação de um corpo que não quer ser visto, invisível aos olhos, mas fértil à criação. Sua desterritorialização é feita pela arte, inventando um espaço e dando contorno ao esquecimento: o comum que se torna extraordinário em obra. Um agenciamento que não hierarquiza os elementos que o constituem, mas as superpõe no território, encontrando forças que o fazem subir à superfície.

A poética da prática banal dá voz a estas singularidades, colocando o comum como objetoarte político e traçando as marcas e vestígios do abandono. Descodificando a ordem estabelecida, embutindo uma variação pelo uso do discurso indireto, experimenta as sensações livre de interpretações: proporciona encontros.

Desta forma, uma Obra-Aula surge a partir desse território existencial circunscrito que "marca as distâncias em relação a outrem e protege do caos" (ZOURABICHVILI, 2009, p. 46). Um modo de se fazer educação como se faz arte, dispensando os modelos e saturados de bom professorado (CORAZZA, 2013), contribuindo ao pensamento acerca da prática docente na contemporaneidade. Ela diz de novas maneiras de montar-fazer-dizer sobre o ordinário. A série de trabalhos Ob.so.les.cên.ci.a (2017), e seus processos, procedimentos e criações, investe no cotidiano como forma de experimentar o território em que se habita. 
Figura 1: Voo, fotografia da série Ob.so.les.cên.ci.a, 2017

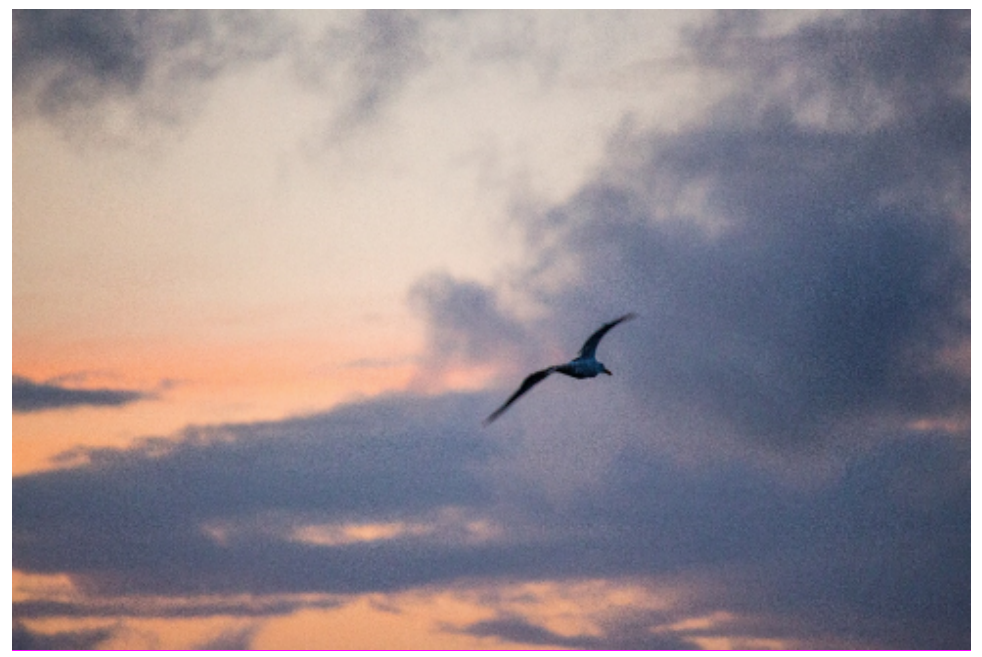

Fonte: Arquivo pessoal

Os elementos deste território dispõem-se em séries, objetos-lugares que compõem obras. Colocando em variação o que apenas reproduz, as desterritorializações movimentam o traçado do plano de consistência, protegendo-se do caos, operando por matérias sem forma ao invés de substâncias formadas.

O processo é o território montado pelo artista-pesquisador, onde busca as suas matérias e pensamento. Fazendo procedimentos que compõem os trajetos de uma geografia, desterritorializase pelo movimento dos fazeres. Uma prática que tensiona as formas de conteúdo e expressão a ganharem novos contornos ou uma nova terra (DELEUZE, GUATTARI, 2011c): criar. Assim surgem os encontros distribuídos pelos afectos numa imagem transformável e manejável de um devir artista-cartógrafo, "[...] repousando sobre 'as coisas do esquecimento e os lugares de passagem"” (DELEUZE, 2011, p. 89).

A série Ob.so.les.cên.ci.a arranja um território que pensa o seu próprio fazer. Trazendo à superfície significâncias (DELEUZE, GUATTARI, 2011b), encontra nos procedimentos artísticos as suposições as formas de conteúdo e expressão para construir um agenciamento, pois "[...] é a significância ou a subjetivação que supõem um agenciamento, não o inverso" (DELEUZE; GUATTARI, 2011b, p. 103). Logo, as criações surgem no seio de uma máquina abstrata que "[...] opera por matéria, e não por substância” (DELEUZE, GUATTARI, 2011b, p. 104), retendo os picos de desterritorialização ou em novas formas, ou em novas terras.

Os trabalhos que o artista-pesquisador recorta e seleciona como objeto deste artigo operam sem a necessidade de formas definitivas, conservando "[...] um bloco de sensações, [...] composto de perceptos e afectos" (DELEUZE, GUATTARI, 2010, p. 193), afastando-se da ordenação do território ao orientá-lo num caminho único. Ao criar um plano de composição para a vida, proporciona “[...] liberar todas as sensações que ela contém” (DELEUZE, GUATTARI, 2010, p. 232). Desta forma, atravessa-o com agregados sensíveis que dispensa as totalizações e estruturas rígidas. Os fluxos que movimentam tal plano deixam orientar-se em novos arranjos, sentidos e texturas.

Este artigo usa de um devir pássaro como força que movimenta os elementos de seu território. Assim, como método, ao modo de uma cartografia (DELEUZE, 2011), se monta numa geografia heterogênea, utilizando-se das caoides (DELEUZE, GUATTARI, 2010) para compor um plano de consistência habitado por afectos das mais variadas ordens. Descartam-se os modelos 
prontos, investindo na exploração dos “[...] meios, por trajetos dinâmicos, [...] [traçando] o mapa correspondente" (DELEUZE, 2011, p. 83).

O meio deste passarinhar é construído por uma multiplicidade de matérias que, aos poucos, ganham consistência, criando uma nova terra que surge dessa superposição. Aqui eles são feitos "[...] de qualidades, substâncias, potências e acontecimentos" (DELEUZE, 2011, p. 83). Essas propriedades são levantadas conforme o pesquisador dá densidade à geografia da pesquisa.

Antes de olhar para as obras, percebe-se um meio, "[...] o percurso e o percorrido" (DELEUZE, 2011, p. 86) de um mapa traçado pelo artista. O resultado exposto é:

[...] como pássaros que batem com o bico na janela. Não se trata de interpretálos. Trata-se antes de detectar sua trajetória para ver se podem servir de indicadores de novos universos de referência suscetível de adquirirem uma consistência suficiente para revirar uma situação (DELEUZE, 2011, p. 86).

Trata-se de perceber a intensidade além da extensidade produzidas pelos trajetos e afectos. Olhar para o processo, procedimentos e criação como habitantes de um mapa que não cessa de vazar e agenciá-los com a Obra-Aula. Assim, os trabalhos, ao invés de objetos inertes, mostram o modo pelo qual foram feitas.

Fragmento por fragmento, o pássaro vai colhendo ao seu redor pequenos objetos coloridos. Montando e dispondo um cenário com os elementos encontrados, vasculha um chão repleto de tons verdes e marrons e descobre um tesouro: o lixo extratonal. Seria pouco dizer que quer chamar um parceiro, ou menos ainda que quer deixar tudo bonito, quando o que ele faz é inventar e erguer “[...] suas casas sobre ele" (DELEUZE, GUATTARI, 2010, p. 232), e "[...] traçar o mapa correspondente" (DELEUZE, 2011, p. 83). As séries evidenciam-se ao deslocar-se pelos meios que exploraram uma maneira de se fazer, mostrando ao público a banalidade das situações percorridas.

\section{SÉRIE OB.SO.LES.CÊN.CI.A}

A série artística Ob.so.les.cên.ci.a ganha contorno conforme os procedimentos montam o processo, criando um fazer-obra. Ao percorrer o mesmo lugar por muitas vezes, varia-se pela reinvenção: voar como se nunca tivesse voado antes. Assim como Kaprow (2003, 2004), o processo desta série investe em um território cotidiano como forma de pensar. Deste modo, a matériapensamento, ao invés de procurar algo fora do comum, busca, na banalidade do deslocamento de um lugar conhecido: suas pistas. Montando um fazer de artista que articula com as forças que são encontradas, percebe-se, no trivial, um desdobramento em arte: maneiras de reinventar as ações rotineiras.

$\mathrm{O}$ artistarinho encontra, no meio de uma mancha cinza, uma pequena flor nascendo. Observa-a por um tempo, percebendo que ela não é uma flor qualquer, mas uma feita de fiapos. Parecia que estava achatada, mas, mesmo emaranhada, era perceptível que algumas linhas tinham cores não reconhecíveis. Brilhava como uma estrela, mas não emitia luz, era um vórtice na verdade. Ficava um longo tempo encarando-a para ver suas sutilezas.

As matérias que compõem o pensamento desta série são mostradas conforme as questões são produzidas. Para tanto, uma orientação começa a montar o processo, e perguntas surgem: Como encontrar potência em um território cotidiano? Como referir algo que não salta aos olhos? Ao persegui-las, pistas de como proceder começam a surgir e maneiras de habitar o plano vão ganhando consistência. Como pode-se criar uma aula como se cria um trabalho em arte?

Os lugares que deram mote a esta produção foram Senandes e os molhes da barra da Praia do Cassino, ambos no município de Rio Grande - Rio Grande do Sul. O processo que levou o 
artista a estes espaços foi a rotina. De tanto passar por ali, parecia um lugar esgotado, como se não houvesse mais nada de novo: era tudo banal. Assim, reinventar o lugar procedeu-se com uma forma de encontrar, pela fome, algo a se pensar (DELEUZE, GUATTARI, 2015).

Mesmo desgastado, puído, há de se encontrar formas de reinventá-lo. Segundo Silva, no prefácio do livro Tentativa de esgotamento de um lugar parisiense, de Georges Perec, "[...] lançar um olhar curioso sobre a Cidade, distende o tempo e as coisas banais do dia a dia e traz à tona uma possibilidade de fazer a Cidade enquanto não se faz nada" (SILVA, 2016, p. 7). Logo, para dizer sobre o local, desorganizou-se sua função sedimentada, o deslocamento, inventando um estado de corpo propício a captar singularidades (CORAZZA, 2013).

O Senandes inicialmente foi concebido como um parque industrial para ser ocupado por indústrias e empresas que quisessem explorar a saída rápida e facilitada ao Porto, mas, por algum motivo, acabou permanecendo inabitado. Seu plano de mobilidade foi concluído, e duas grandes áreas receberam asfalto e uma ligação à estrada federal que liga a cidade ao Porto, com a linha férrea. Uma via foi recentemente feita, ligando-o à praia do Cassino, fazendo esse lugar uma espécie de rota alternativa (e pouco fiscalizada) de acesso praia-cidade.

Figura 2: Desenhos e anotações: rastros da série Ob.so.les.cên.ci.a, 2017

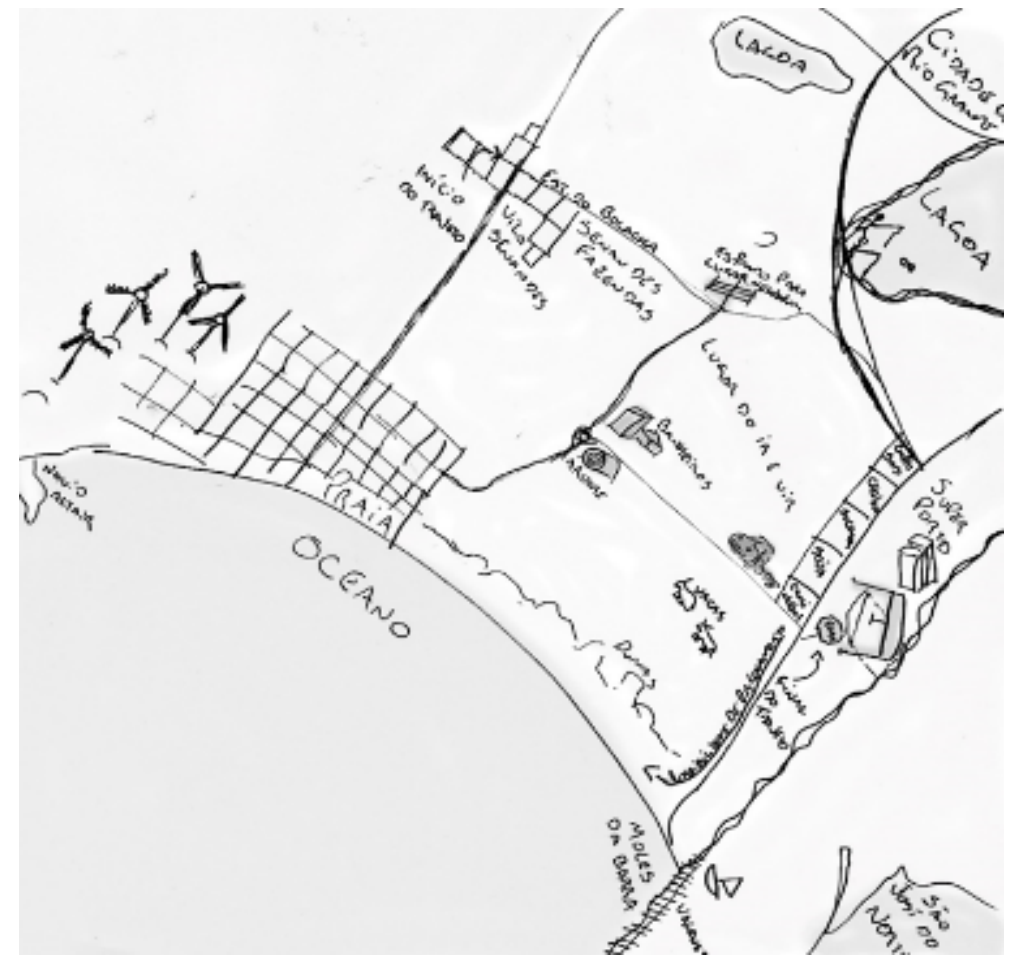

Fonte: Arquivo pessoal

Como um primeiro modo de entrar nestes lugares conhecidos, um guia do que é comum foi desenhado. Um início de procedimento, onde o artista coloca tudo aquilo que desperta interesse e lhe é facilmente reconhecido em uma espécie de catálogo-inventário, localizando geograficamente os seus interesses. Um modo de dizer sobre os pontos que habitam o espaço e, assim, medir as distâncias iniciais, colocando as frequências preponderantes a ressoarem num ritmo (KASTRUP, PASSOS, 2013). O artistarinho sentiu-se desprotegido, voou até o ponto mais alto que conhecia e flauteou todas as notas que conhecia, na esperança de que algum outro pássaro lhe retornasse. 
Os objetos-monumentos surgiram. Guindastes que levam os contêineres dos navios até os caminhões se destacam. Também o dique seco ${ }^{1}$, que possui um pórtico de oitenta metros de altura, destaca-se no horizonte. Alguns outros pontos também surgem, em menor escala, mas apontando para uma visão mais específica do deslocamento. A placa escrita "não pare viver", o caminhão verde despedaçado, o banheiro químico caído são observações corriqueiras de quem se desloca pelo local.

Figura 3: Savana, fotografia da série Ob.so.les.cên.ci.a, 2017

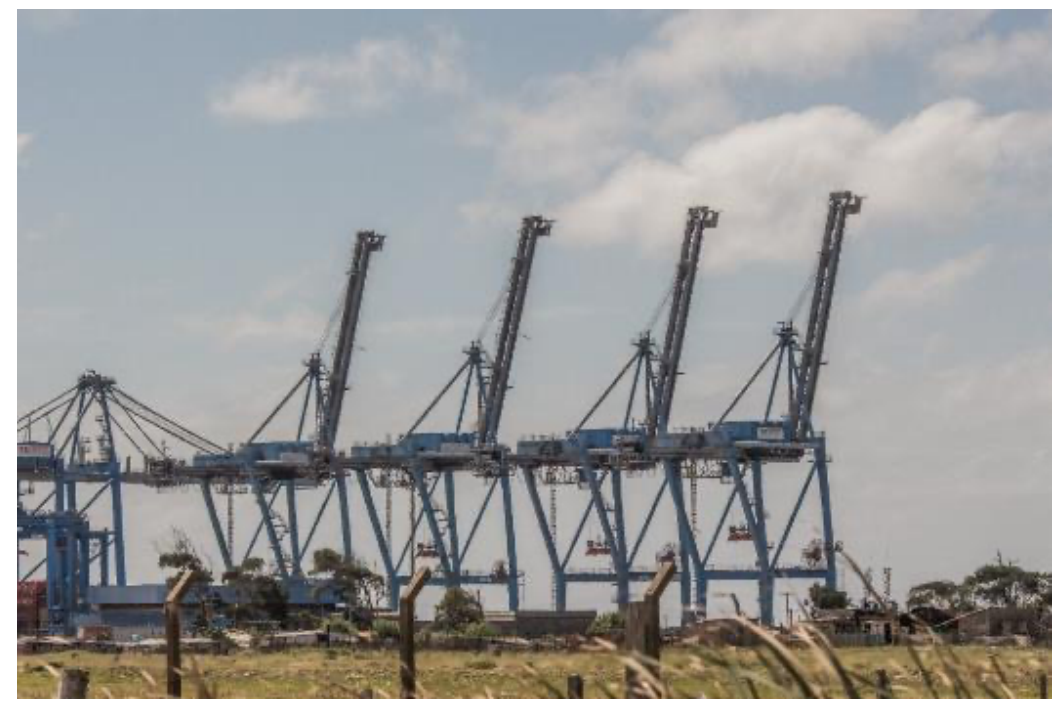

Fonte: Arquivo pessoal

Uma delimitação do espaço do deslocamento e das peças da construção das plataformas petroleiras também estão presentes. Essas descrições funcionam para movimentar um pensamento sobre o lugar, uma desterritorialização relativa aos estratos que compõem o território geográfico. São os pequenos detalhes que se mostram mais interessantes, como o tronco de árvore queimado, em um lugar onde não há árvores e a cerca que fecha uma estrada de asfalto.

Esta primeira etapa faz fugir ao território comum, mas ainda é relativa aos seus estratos (DELEUZE, GUATTARI, 2011b), referindo-se a um organismo interpretativo e dado. Para uma desterritorialização mais consistente, uma que seja absoluta, vai-se ao encontro de um espaço livre de significações: uma máquina abstrata (DELEUZE, GUATTARI, 2011b). Uma Obra-Aula não recorre a modelos prontos, tem que ser agenciada com matérias ainda em formação.

Para montar um plano de consistência que atinja esse alto pico de desterritorialização, há que se encontrar "[...] sua própria positividade potencial” (DELEUZE, GUATTARI, 2011b, p. 94). Logo, “[...] fazer da consciência uma experimentação de vida, e da paixão um campo de intensidades contínuas, uma emissão de signos-partículas" (DELEUZE, GUATTARI, 2011b, p. 94-95) é abandonar as certezas, os significados e as significâncias que o artista tem do local, deixando de ser sujeitado como um ser que se desloca por pontos e tornar-se uma linha.

O artistarinho lembrou que Duchamp se apropriava dos ninhos alheios. Não era um roubo material e, sim, um furto expressivo, já que transformava os ninhos em obras apenas dizendo: é meu. Isto intrigava o pequeno pássaro, pois qual era o vetor que fazia tal transformação? Todos os

${ }^{1}$ http://www.sengers.org.br/site/noticias/407/complexo-do-dique-seco-de-rio-grande, acesso dia 09 de ago. 2020. 
ninhos eram passíveis de serem modificados? Daí veio sua grande surpresa: descobriu que são apenas os ninhos onde o artista põe ovos.

Figura 4: Ponte do Bolaxa, fotografias da série Ob.so.les.cên.ci.a, 2017

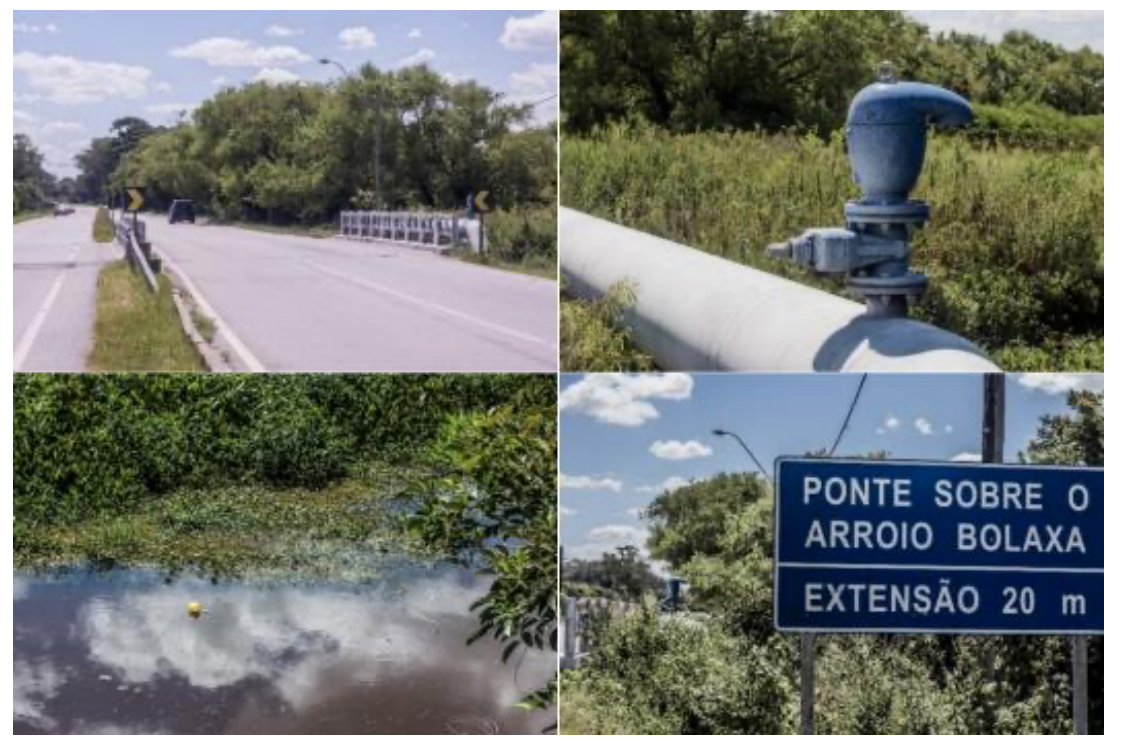

Fonte: Arquivo pessoal

Ao comparar esse desenho com uma foto de satélite do Google Mapas, o artista percebe que uma das entradas era a menos acessada por ele. Uma estrada de chão batido, com vários pequenos sítios, próxima ao Arroio Bolaxa, havia passado desapercebida. Esta era uma via pouco usada para chegar tanto à praia quanto ao porto, pois era de chão batido e fazia um percurso mais longo. Esta foi então dada como ponto de partida para um novo deslocamento a ser feito.

O artista leva consigo uma câmera, que lhe permite fotografar e, também, gravar vídeos, além de um caderno de anotações. Ainda sem um rumo certo, apenas com uma entrada programada e uma vaga desconfiança do caminho a ser percorrido, entra no Senandes pelo acesso próximo à ponte do Arroio Bolaxa. Uma sensação de estranheza ao percorrer um caminho já conhecido, mas que agora, com uma orientação de redescobri-lo, é tensionada.

Iniciando a segunda etapa, pela rota não programada, depara-se com vários pequenos sítios. Ao percorrer este caminho, percebeu que o lugar era uma toca: várias entradas e várias saídas, mas que, por algum motivo, havia apenas uma rota utilizada. A maneira de cruzar esse território parece não variar, mesmo havendo algumas outras.

O artistarinho começa a compor uma nova rota, um jeito diferente de percorrer o seu habitat. Ele percebe que coloca ovos em ninhos que nunca havia visto, mesmo estando em seu território. Apropriou-se de alguns, fez proliferar voos com outros pássaros e, encantado com os outros modos, batia as asas de felicidade. Uma Obra-Aula não sabe por onde começar, mas sabe que recorrer ao dogmatismo não é seu processo.

Ao abandonar a rotina, depara-se com algo ainda não visto: as porteiras das pequenas fazendas. Ao passar por elas (antes as via apenas de longe, como um ruído harmonioso), lhe dizem algo: por mais que se passe por um lugar, sempre há algo ainda a se descobrir. As sutilezas são infinitas, reinventando o que está posto. Há várias formas, redistribuindo os afetos e/ou dando consistência aos pontos. Ao tensionar o território com novas forças e rotas, compôs um novo lugar, ainda irreconhecível ao olho: uma pintura não retiniana (PAZ, 2010). O bico do artistarinho 
mudou de forma, ficou mais comprido e fino, adaptou-se às mudanças que a nova rota lhe proporcionou: abriu frestas em troncos grossos.

Um signo que cansou de remeter-se aos mesmos signos numa circularidade indisponível a novos afectos, escapando e proliferando outras combinações (DELEUZE, GUATTARI, 2011b). Estas novas relações formaram um rizoma, relacionando-se livremente sem a ordem do deslocamento rotineiro, escapando do significante que quer o cortá-lo (DELEUZE, GUATTARI, 2011a).

Operando num mesmo lugar e trajeto, a intensidade foi alterada com outras relações que entraram em ressonância. Cada ponto faz vibrar os elementos do território, criando zonas de aderência e conectando-se a outros, uma sinfonia flauteada por diversos passarinhos com diferentes arranjos. A nova rota expandiu-se, vislumbrando "[...] uma arte-cartografia, que repousa sobre [...] os lugares de passagem', [...] [não bastando] dizer que ela é paisagem e que ordena um lugar, um território. Ela ordena caminhos, ela mesma é uma viagem”. (DELEUZE, 2011, p. 89).

Foram feitas fotografias desta rota, e alguns objetos-lugares surgem com novas forças. Entra-se na terceira etapa do procedimento: olhar o material capturado e dar novos sentidos ao que antes era único. A sensação começa a preencher as lacunas da falta de significado (GIL, 2010). Assim como Malevich, uma gramática da sensação vai constituindo um espaço, os objetos vão perdendo seu uso organizado para ganhar novas formas.

Um ninho de pássaro dentro de um rolo de cabos de fibra ótica repetia-se na paisagem, nunca haviam sido notados antes. Estes fios serviriam para algum fim, tinham um significado, mas o pássaro o habitou, colocando um ovo nele. $\mathrm{O}$ artistarinho colocou outro. Movimentadas por uma desterritorialização absoluta, porém negativa (DELEUZE, GUATTARI, 2011b, 2011c), apontam novas relações engendradas com sensações, reterritorializadas nas novas formas que o território ganhou.

Figura 5: Ninho de fios, fotografia da série Ob.so.les.cên.ci.a, 2017

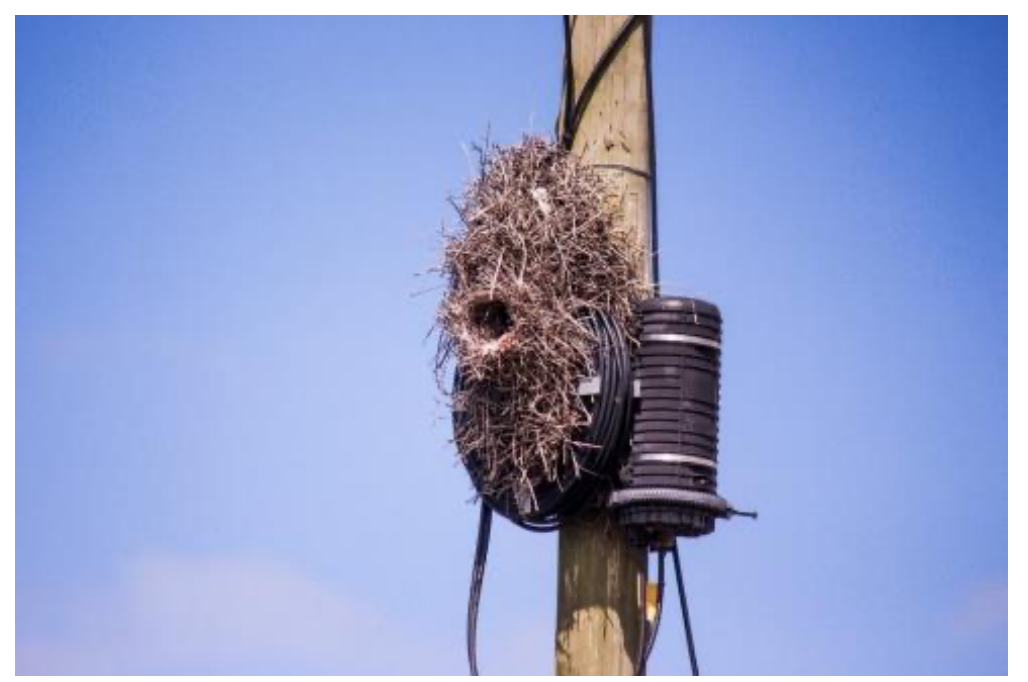

Fonte: Arquivo pessoal

Outras maneiras de relacionar-se com o que está a volta. Este agenciamento mostrou o exercício de pensar: o porquê de os objetos-lugares estarem naquele lugar. Questionamentos levantaram novas inquietações sobre o processo. As sensações passam a mover os procedimentos, que, por sua vez, se montam conforme a série de obras se movimenta: uma maneira mútua de pensar o fazer artístico. Abandonando protocolos, modelos e rotas fixas, o território ganha 
variações mesmo sem perder sua orientação. Uma Obra-Aula dá atenção àquilo que não é predeterminado.

A desterritorialização alcança alguns picos absolutos, mas ainda surge na subjetivação (DELEUZE, GUATTARI, 2011b) ao retornar aos estratos (mesmo que com novas formas em seu grau negativo). O território ainda permanece com o mesmo contorno. Mesmo deslocando-se por uma rota menos provável, rastros do que já era dado se repetem, e o que se produz como imagem é ainda uma representação do abandono.

Para investir numa força mais potente que transforme os objetos-lugares (que ainda insistem em fazer relação com o catálogo-inventário), desenharam-se novas semióticas, habitando outros afetos e favorecendo variados encontros. Logo, perguntas surgem para orientar as modificações que estão pedindo passagem: Quais forças percorrem o território? Quais minoridades pedem passagem? Qual o povo que está por vir?

Encontra-se um problema, as fotografias feitas buscam um bom gosto (PAZ, 2014), ao juntar convencionalidades estruturais do que se espera ser agradável aos olhos. Assim como O Rei Midas, que toca os objetos-lugares e os deixa reluzir, prosperar, beneficiando poucos em detrimento de muitos. A forma pela qual essas fotos se apresentam faz fracassar e obriga o artista a buscar algo novo: o intangível. O sensível então deve ser encontrado.

Figura 6: Estrada interrompida, fotografia da série Ob.so.les.cên.ci.a, 2017

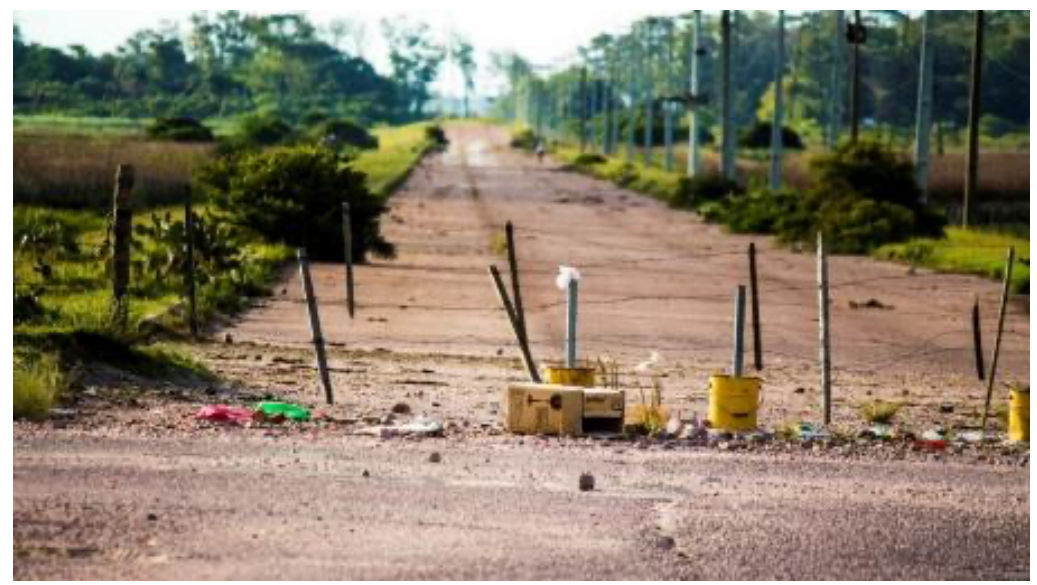

Fonte: Arquivo pessoal

Então o quarto procedimento se monta: abandonar as formas rígidas. Ao percorrer o espaço com novas perguntas, as sutilezas começam a se mostrar. A rota põe em variação, distribuindo fortes lufadas (CORAZZA, 2013) que agora as habitam e orientam o fazer do artista.

Encontram-se forças que delineiam outros contornos ao território. Os guindastes não parecem mais com animais, eles o são e habitam o horizonte disputando a territorialidade com o artistarinho. O pássaro não faz um ninho dentro de fios de fibra ótica, ele é a própria luz que viaja em velocidades infinitas. A placa que diz para não parar de viver torna-se uma vida nela mesma. 

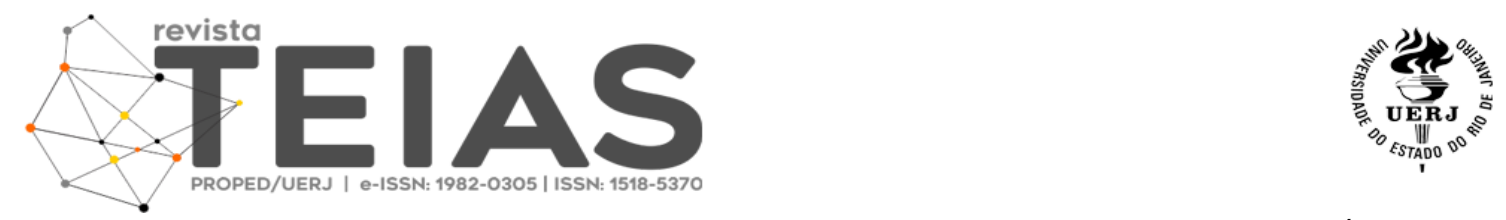

DOI: $10.12957 /$ teias.\%Y.53650

Figura 7: Não pare de viver, fotografia da série Ob.so.les.cên.ci.a, 2017

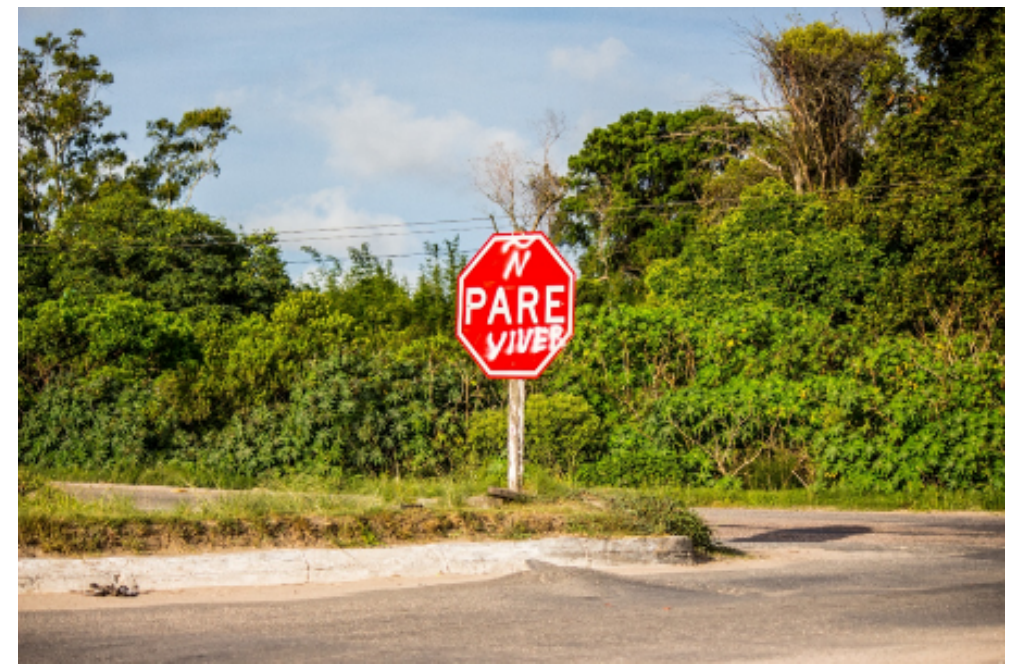

Fonte: Arquivo pessoal

A série agora discute a si mesmo como se fosse aumentada num microscópio (DELEUZE, GUATTARI, 2015). Os conflitos caros ao artista são evidenciados e colocados numa rota que diz sobre ela mesmo, dispensando os sujeitos de enunciação individuados (DELEUZE, GUATTARI, 2015). Para tanto, encontra, na enunciação coletiva, "[...] seu próprio ponto de subdesenvolvimento, seu próprio dialeto, seu próprio terceiro mundo, seu próprio deserto" (DELEUZE, GUATTARI, 2015, p. 39). Às margens do território, o artistarinho convoca os que faltam: os que põem a variar as rotas já organizadas.

Figura 8: Rede-Barra, fotografia da série Ob.so.les.cên.ci.a, 2017

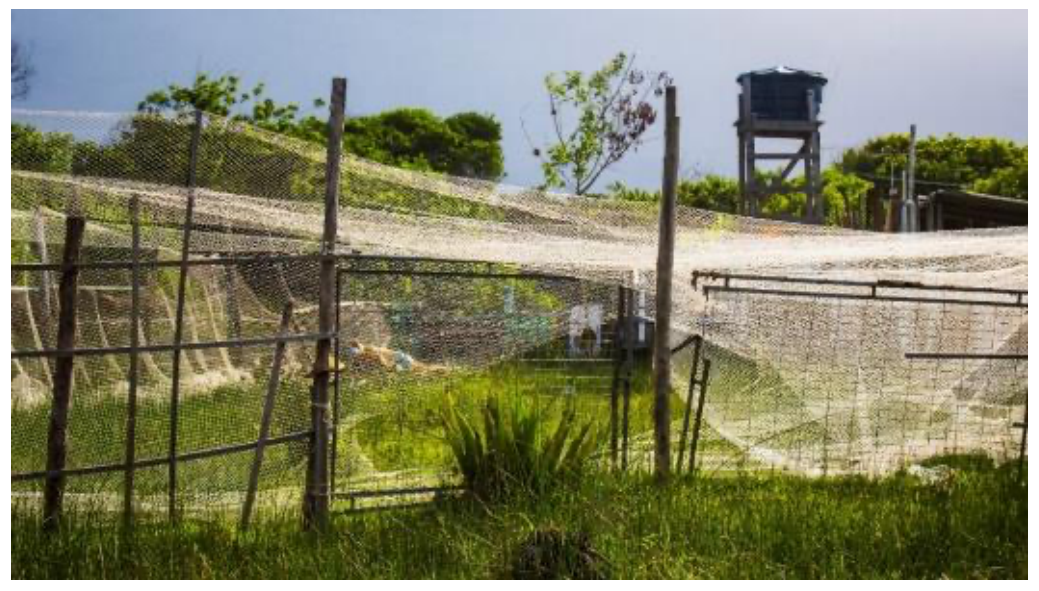

Fonte: Arquivo pessoal

O deslocamento encontra suas forças ao pôr em relação regimes semióticos distintos, engendrando transformações que convoquem um coletivo ainda por vir. Abandonando analogias, símbolos, polêmicas e mimeses, investe no diagrama que cruza os vetores que habitam os planos de consistência (DELEUZE, GUATTARI, 2011b, 2011c). O ponto mais alto de desterritorialização, absoluta e positiva, monta um plano de consistência e habita uma máquina abstrata (DELEUZE, GUATTARI, 2011b, 2011c). 
Essas transformações colocam em prática novos regimes de signos mistos que habitam os territórios deste deslocamento. A arte faz com que ganhem misturas em semióticas estranhas e selvagens (CORAZZA, 2013). Mas, para chegar a essa mudança, evidenciaram-se, nos procedimentos anteriores, suas formas de expressão e conteúdo, montando um agenciamento que fez vazar o que já é dado: o agenciamento é suposto pelas formas que o constituem (DELEUZE, GUATTARI, 2011b). Uma Obra-Aula recorre ao que lhe é estrangeiro, cria a sua diferença.

Os procedimentos da série passaram a servir como modo de montagem do pensamento: rotas que engendram a criação. As formas de conteúdo e expressão evidenciadas por eles mostraram os rastros de um abandono. As maneiras pelas quais o artista supôs o espaço variaram, novos percursos foram inventados para dizer o que ainda não havia sido dito. Observando o seu próprio deslocamento, percebem-se as forças que o habitavam: o artistarinho encontra uma nova terra (DELEUZE, GUATTARI, 2011b, 2011c). Esta transformação dispensa reterritorializar-se em antigos estratos, pois cria uma fenda no território, modificando seu contorno.

A série Ob.so.les.cên.ci.a monta um território, partindo da observação de um lugar comumente percorrido pelo artista. A forma de expressão é montada pela série de fotos, vídeos e anotações que o artista gerou de um lugar esquecido e abandonado. Transformados incorporeamente, os objetos e espaços se modificam, e o reorganizam com os novos usos.

Assim como Kaprow, o artista se inseriu em processos, evidenciando os procedimentos e transformando-os como sua criação. As obras que resultam do processo ainda são efeitos das rotas perseguidas, que mostram como o artista percorreu o seu meio. Ao dizer sobre o habitat, e flautear as suas margens, o artistarinho conseguiu pensar em novos caminhos, encontrando frutos e colocando ovos em ninhos estranhos.

E a série começa a criar-se, por fotos, vídeos e desenhos que dizem sobre as forças de um lugar: novas intensidades. Monta-se uma sequência de fotografias como se fosse um alfabeto de forças que povoam o abandono. Assim como Malevich esvaziou-se das formas representativas para deixar subir à superfície a sensação, a série Ob.so.les.cên.ci.a abandona a busca pelas formas para encontrar os vetores do território.

O trabalho constituiu-se em série e isto não foi algo desenhado previamente. Percebendo que elas diziam de um lugar, e não de coisas isoladamente, o artista teve a liberdade de rearranjar as obras, trabalhando conforme percebia as suas potências. Cada exposição ${ }^{2}$ ganha um novo recorte, e novas gramáticas surgem.

Logo, para criar, é preciso que algo force o pensamento, tire ele de sua zona comum: “[...] é preciso haver uma necessidade, [...] caso contrário não há nada” (DELEUZE, 2016, p. 333). Assim, surge em uma dupla via que se articula: uma força que rompe com o estado cotidiano; uma fome e escassez de formas representativas. Ao mostrar os vetores que atravessaram o espaçoobjeto que se deslocou, rompe-se com a obrigatoriedade de haver uma referência, deixando surgir o deslocamento por ele mesmo em fotografias, vídeos e desenhos.

A série constrói-se pelos seus fragmentos, não havendo a obrigação de referenciar-se à representação de um território geográfico. Parafraseando Bresson, Deleuze (2016, p. 335) diz que "[...] se passa como se [...] apresentasse como uma série de pequenos pedaços cuja conexão não é predeterminada", deixando que as obras deixem as sensações livres para ganharem contorno na medida em que são evidenciadas.

\section{OBRA-AULA}

\footnotetext{
2 Esta série já foi apresentada em duas situações distintas, na exposição DESLOCC: As Paisagens Cotidianas (2018) e Fresta - Mostra Audiovisual (2018).
} 
Pensar as práticas docentes como se pensa os processos de artista é colocar a educação a dispensar os ditos bons modelos (CORAZZA, 2013) e agenciar com uma poética capaz de inventar novas maneiras de se fazer. Ao criar uma aula como se cria arte, os processos e os procedimentos se colocam como forma operacional. Ao oferecer o seu modo, o artistarinho revela a potência que dispensa imitar outros sons e acompanha o deslocamento, reinventando-o.

Desta maneira, a aula é uma cartografia dos pássaros, onde as rotas servem como formas de variar o processo, onde novos encontros se façam, mesmo num território saturado. A série Ob.so.les.cên.ci.a é uma sequência de rotas como uma toca (DELEUZE, GUATTARI, 2011a), um lugar onde o animal varia as entradas e as saídas, bem como suas zonas íntimas e estratificadas.

O artistarinho está preocupado em voar, habitando o ambiente, dispensando um caminho predefinido. Observando e conhecendo os contornos e seu território, ele põe a variar diversos encontros nos percursos que são tensionados: uma nova terra é rodeada de frutos, ninhos e revoadas.

Ao criar, tanto o artista quanto o docente utilizam-se de um agregado sensível (o próprio cotidiano), colocando-o em situações ainda impensadas: o que é passível de se inventar. O comum é tensionado a encontros que confrontam sua invisibilidade, tornando-o visível pela arte e experimentando formas de vazar as estruturas.

Para isso, experimenta-se o seu território de amplas maneiras. Um conteúdo curricular, por exemplo, não tem uma forma expressiva única, nem um modelo de práxis a ser seguido. Muda-se a perspectiva, deixando-o ser um "lugar de passagem" (DELEUZE, 2011, p. 89) passível de ser atravessada por diversas rotas diferentes. Os caminhos certos apenas reproduzem formas prontas, dificultando a variação. Assim se privilegia "[...] a mobilidade perpétua do real [...], [criando] por meio de experimentações" (CORAZZA, 2013, p. 23), encontrando forças para a docência "[...] que não para nunca de se deter no jogo da sua própria proliferação" (CORAZZA, 2013, p. 23).

O habitat agora estava disposto, o artistarinho sentia-se vigoroso. A cada rota criada, encontros potencializaram seu passarinhar, a sua força recebia energia em cada pouso e em cada voo. Enchia o peito e lufava sons de qualquer parte do território, pois recebia a ressonância das revoadas que ele convocou. É bem certo que este canto era estranho, parecia gaguejar, não soava como dos outros pássaros.

Ao dizer sobre sua produção, o pesquisador-artista mostra, nos processos, os procedimentos que criam as séries. Logo, pelas forças que as conduzem, as matérias-pensamentos entram em relação com as maneiras de se fazer a produção poética. O conteúdo de uma aula é visto como uma série, onde aproxima e mede as distâncias entre seus elementos constitutivos, encontrando formas heterogênea de transformação. Este é um trajeto que não cessa de variar pelo dinamismo de explorar o meio e traçar mapas (DELEUZE, 2011).

Para tanto, acompanham-se as variações e encontros. A docência que acompanhar os procedimentos, dispensando os já prontos, modelizados e instaurados, favorece afectações propiciadas pelas proliferações das ressonâncias arteiras. Nessa direção, a criação surge na contramão do referir a algo já dado, investir no que ainda está por vir, dispensando formas prontas. Logo, ao construir uma Obra-Aula, o artista-professor localiza os elementos constitutivos de seu território e os define como seus, transformando-os em um geopensamento: o processo de um professor-artista.

As rotas e os procedimentos, fazem o território ganhar novos contornos e encontros, ignorando barreiras que deixam as relações intransponíveis e que forçam o retorno a antigos percursos. Quando o artista-pesquisador se depara com sua vaidade técnica na fotografia, percebe o quão limitante é esse caminho que estava adotando. Foi abandonado o juízo de gosto (PAZ, 2014), descartando a boa aparência para uma experimentação livre de opiniões. 
Os atos rotineiros passam a ser o meio pelo qual outras rotas surjam. É indispensável que eles existam, mas também que se deixem proliferar, percorrendo sua geografia. Explorar o seu território e experimentá-lo (novamente de diversas formas) é habitar as obsolescências com novas perspectivas potencializadores de encontros.

Uma Obra-Aula passarinhada pondo em fuga os modelos. Um investimento procedimental no que está à volta para inventá-la: reinventar o banal. Permanecendo atento ao que o rodeia, dando novos usos ao que antes era invisível, "[...] teria alcançado um limiar absoluto da desterritorialização" (DELEUZE, GUATTARI, 2011b, p. 36) sem precisar referir-se aos modelos dados. Mas, para isso, suporta a falta de sentidos únicos, deixando a sensação operar as lacunas, fazendo-se como rumores de uma arte de linguagem.

Artistas e professores estão imersos em processos que mostram as criações pelos procedimentos que os ocupam, pondo em variação suas obras e aulas. Ao colocar em um plano comum as maneiras pelas quais se faz, percebem as forças que devém a criação. Assim, supõem os agenciamentos capazes de formalizar os conteúdos e expressões em novas modificações.

Para criar sua aula, o professor conhece seu território, o lugar por onde fará seus trajetos. Localizando os elementos que o compõem, o docente cria uma geografia de seu ambiente, inventando maneiras de circular por entre eles. Dá fôlego aos modelos que ignoram as peculiaridades de cada ambiente. A diversidade e o saber de um habitat é que coloca em movimento a potência de um pássaro.

O processo é o território montado pelo artista-pesquisador, onde busca as suas matérias e pensamento. Mas é pelos procedimentos que se compõem os trajetos de uma geografia. A desterritorialização movimenta os fazeres; uma prática que tensiona as formas de conteúdo e expressão a ganharem novos contornos ou uma nova terra (DELEUZE, GUATTARI, 2011c): criar. Assim surgem os encontros, proporcionando e distribuindo afectos numa imagem transformável e manejável de um devir artista-cartógrafo: "[...] repousando sobre 'as coisas do esquecimento e os lugares de passagem"' (DELEUZE, 2011, p. 89).

O artistarinho encontra essa nova terra, mas ainda não consegue dizer sobre ela muito bem, mas sabe que é feita pelos encontros caoides entre educação, arte e filosofia. Ele bica os frutos que encontra, usa suas garras para segurá-los. Está atento aos novos arranjos desse habitat, e não deixa de levar em conta a intuição de pássaro.

Ao pôr em movimento as matérias no pensamento, percebe-se como a composição de diferentes elementos entram em relação, "[...] colocando em jogo não somente regime de signos diferentes, mas também estatuto de estado de coisas" (DELEUZE; GUATTARI, 2011a, p. 22). Atravessados pela experimentação, vazam as estruturas. Engendrando procedimentos, coloca-as em transformação as forças que ligam a heterogeneidade.

Duchamp faz isso ao propor uma zona invisível: ir além do que a visão mostra das obras (PAZ, 2014). Seu interesse é no pensamento que surge das obras, uma constante mutação que põe a variar os significados. O docente também transpõe as grades curriculares, movimentando aquilo que a educação coloca na superfície e voando por entre frestas. Bicar os conteúdos educacionais é transcriar (CORAZZA, 2011) passarinhando.

O agenciamento oriundo dos ready-mades estão sempre em constante desterritorialização, pois não se definem nas formas já dadas de um território. Um docente-artista, ao conhecer sua geografia, articula diferentes matérias (de conteúdos já programados), encontrando outras maneiras de colocá-las em suas aulas. Os procedimentos, oriundos de suas experimentações, são agenciados. Fazendo-os perder a distinção de suas formas, engendram novas práticas docentes.

O processo é o plano onde a composição ganha força. Um conjunto superposto de matérias, pensamentos, ações e modos de fazer que, envolvidos em procedimentos, engendram criações. Não existe um modelo único de como fazer arte e docência, pois depende de um modo 
pelo qual os elementos do território irão se relacionar, compondo práticas pelas forças e trajetos num meio. Durante o seu andamento, surgem pistas: movimentos e operações de como é aferida.

Um artistarinho cansou de imitar sempre as mesmas notas. Seu bico não tinha mais força para isso: cria outros sons. Voou até um canto do seu habitat, ensaiou esquisitices, tinha uma desconfiança que isso lhe renderia algo. Aos poucos, outros pássaros começaram a escutar, as cabeças desconfiadas não paravam de procurá-lo.

Um fôlego à docência com "[...] novas e fortes lufadas de enunciação, que nos leva a pensar e a viver a Educação do mesmo modo que um artista pensa e vive a sua arte" (CORAZZA, 2013, p. 19). A arte além de forma expressiva, mas como um modo de encarar os meios, encontrar trajetos e traçar os mapas.

Um processo artístico-educacional que se constrói em vizinhança com vetores passarinheiros, encontrando, nos procedimentos, novas maneiras de se pensar. Desta forma, é olhando um espaço comum que a banalidade surge pelas frestas que se abrem. Explorar um território em que pululam encontros e esperar os afectos a povoarem. E devir pássaro.

Kaprow (2010) convida o público a ser artista, desempenhando papéis cotidianos como maneiras de fazer arte. Orquestrar ações e experimentações no/do comum, reinventando-as sem as ordenações corriqueiras. O espaço, os objetos e os fazeres são compostos de modo a não comandar a atividade e, sim, permitir que o pensamento flua livremente.

Um espaço torna-se obsoleto? Como um território é reinventado? Ao perseguir essas perguntas, orientado pelos descartes de lugares rotineiros e de espaços cotidianos, as séries de obras começam a se fazer pelos rastros encontrados: bicando frutos que parecem secos, mas repletos de força e energia.

O artistarinho descobre que seu habitat está repleto de elementos ainda não percebidos. Seu território ganhou novos contornos, os encontros com Duchamp, Kaprow e Malevich ampliaram a criação de rotas. Flauteou e, ao fundo, escuta a ressonância que fazia com a artistagem docente de Corazza. A sinfonia lufava pelo território.

Desta forma, uma Obra-Aula é a invenção de percursos e perspectivas para um território constituído num plano de consistência: criar procedimentos. A espessura desta docência-artista depende de entrega e engajamento ao desenhá-la. Distribuindo pontos, medindo as distâncias meticulosamente, com o maior número de perspectivas possíveis, aproxima as relações ainda não vistas, sentidas e experimentadas.

\section{CONSIDERAÇÕES}

Ao colocar em movimento processos e procedimentos de artista, uma força passarinhar é criada. Um método à maneira de uma cartografia (DELEUZE, GUATTARI, 2011a) que voa, bica, faz ninhos, encontra parceiros, põe ovos, agarra-se, habita, desloca-se, caminha desengonçado, caga, migra, suga néctar, imita e aprende: adapta-se. Criando trajetos em um território heterogêneo, permanece à espreita das relações futuras: das flores que emanam ultravioleta. Desconfia e persegue em sua territorialidade nas mais diversas e extravagantes formas.

Uma maneira de fazer pesquisa que voa longas distâncias. Como os pássaros que migram em uma geografia cinza e saturada, suas rotas fazem-na ganhar novas cores e colocar essas diversas matérias em relação. Ao se abrir num "[...] plano comum [que] envolve então ampliação e alargamento das subjetividades pela conexão com singularidades heterogêneas e semióticas até então estranhas" (KASTRUP, PASSOS, 2013, p. 276), permite que novas existências sejam possíveis, que as experimentações sejam bicadas, o alimento encontrado e a rota criada. Assim, a arte convoca à educação um povo ainda por vir, que está em falta (DELEUZE, GUATTARI, 
2015), e que há que fazer existir pela arte (já que a educação tanto fez pela poética deste pesquisador, uma troca mais do que justa).

Enquanto procedimento investigatório da ação do passarinhar, foram adotadas rotas no traçado do plano extensivo para uma Obra-Aula. Seu território então se enche de matériaspensamentos, de elementos heterogêneos que são percorridos por trajetos itinerantes por onde pousou. As frutas já bicadas, o canto escutado, a flor vista, colocadas a movimentar-se pela educação, arte, filosofia, tornam-se o colorido que compõe essa nova paisagem. Novas flores que emanam ultravioleta agora são vistas.

A arte possibilita experimentações no mundo, agarra cada fruta que encontra, agitando significações já estabelecidas. Ao pensar sobre as zonas de aproximação do fazer de artista com a artistagem docente, esta pesquisa mostra maneiras de fugir dos moldes representacionais. Ao aproximar esses campos, novas invenções interagem e geram fagulhas propícias à criação pelos encontros que se mostram.

Ao passarinhar diante do caos, um recorte foi adotado para formar as rotas de voo. Um plano de consistência (DELEUZE, GUATTARI, 2011a) orientou um espaço povoado por novos afetos e trajetos. Contagiado, desorganizado e flauteado, seguiu-se numa orientação que estabeleceu aproximações com as matérias ao superpor: criou-se algo novo. Um trajeto, um deslocamento, passível de ser habitado pelas forças da intensidade passarinhar. Os espaços para que os conceitos pudessem encontrar suas potências ganham força ao voarem, operando por afinidades que os movimentaram por lugares ainda desabitados e não sobrevoados: um deserto visto de cima em constante movimento.

Ao escolher compor seu trabalho em séries, o artista tensiona a banalidade, dando a ela uma possibilidade de transformar-se ao reunir os indícios das trivialidades do plano comum. As obras da série Ob.so.les.cên.ci.a, ao invés de montar-se em uma conectividade evidente, agregam forças que dizem sobre as tensões internas que as ligam. São destituídas as ordenações amplas, optando pelos fragmentos (vídeos, fotografias e desenhos) que se relacionam em constante movimento, engendram discursos indiretos que colocam em variação seus contornos.

Ao adotar uma abordagem de pesquisa teórica filosófica para falar de uma prática artísticadocente, distribuíram-se afetos, dotando de potência as imanências. Um plano intensivo foi, aos poucos, sendo arrancado das relações que eram postas, “[...] as forças intensivas subtendem as forças motrizes" (DELEUZE, 2011, p. 88). Compondo-a com as ações artísticas feitas pelo pesquisador (Prática Poética do Banal) e as suas referências artísticas - Allan Kaprow, Kazimir Malevich e Marcel Duchamp -, novos trajetos evocaram fugas das linguagens dominantes e de uma educação presa em modelos (Artistagem de Corazza).

Engendrado em suas referências artísticas, os trabalhos que compõem a Ob.so.les.cên.ci.a fizeram com que o pesquisador-artistarinho os relacionasse com a artistagem docente (CORAZZA, 2013). Portanto, uma Obra-Aula é possibilitada pelo cotidiano, pelo esgotamento e pela invenção, pensamento que convida "[...] uma zona objetiva de indeterminação ou de incerteza, comum e indiscernível; na qual não se pode dizer onde passam as fronteiras de uns e de outros" (CORAZZA, 2013 , p. 26). Uma tentativa de romper com estes modelos prontos é a docência apropriar-se de seus devires artista, ensaiando os conteúdos e os transversalizando, criando, partindo de práticas e matérias-pensamentos que já lhe são parte. Sem imitar, busca, nas formas de criação dos artistas referência, relações que montam aproximação de processos e procedimentos artísticoeducacionais.

\section{REFERÊNCIAS}


CORAZZA, Sandra Mara. Notas para pensar as Oficinas de Transcriação (OsT). In: HEUSER, Ester Maria Dreher (org.). Caderno de notas I: projeto, notas \& ressonâncias. Cuiabá: EdUFMT, 2011. CORAZZA, Sandra Mara. Para artistar a educação: sem ensaio não há inspiração. In: CORAZZA, Sandra Mara. O que se transcrita em educação? Porto Alegre: UFRGS; Doisa, 2013. Cap.1, p. 17-40.

DELEUZE, Gilles. O que as crianças dizem. In: DELEUZE, Gilles. Crítica e clínica. Tradução de Peter Pál Pelbart. São Paulo: Editora 34, 2011. Cap. 9, p. 83-90.

DELEUZE, Gilles. Dois regimes de loucos: texto e entrevista (1975-1995). Tradução: Guilherme Ivo. São Paulo: Editora 34, 2016.

DELEUZE, Gilles; GUATTARI, Félix. O que é a Filosofia? Tradução: Bento Prado Jr. e Alberto Alonso Muñoz. São Paulo: Editora 34, 2010.

DELEUZE, Gilles; GUATTARI, Félix. Mil platôs. Capitalismo e esquizofrenia 2. v. 1. Tradução de Ana Lúcia de Oliveira, Aurélio Guerra Neto e Celia Pinto Costa. São Paulo: Editora 34, 2011a.

DELEUZE, Gilles; GUATTARI, Félix. Mil platôs. Capitalismo e esquizofrenia 2. v. 2. Tradução de Ana Lúcia de Oliveira e Lúcia Cláudia Leão. São Paulo: Editora 34, 2011b.

DELEUZE, Gilles; GUATTARI, Félix. Mil platôs. Capitalismo e esquizofrenia 2. v. 5. Tradução de Peter Pál Pelbart e Janice Caiafa. São Paulo: Editora 34, 2011c.

DELEUZE, Gilles; GUATTARI, Félix. Kafka: por uma literatura menor. Tradução: Cíntia Vieira da Silva. Belo Horizonte: Autêntica, 2015.

GIL, José. A arte como linguagem. A última lição. Lisboa: Relógio D'Água Editores, 2010.

KASTRUP, Virgínia; PASSOS, Eduardo. Cartografar é traçar um plano comum. Fractal, Rev. Psicol. 2013, v. 25, n. 2, p. 263-280.

KAPROW, Allan. A educação do an-artista. Parte I. Concinnitas - Revista do Instituto de Artes da UERJ, Rio de Janeiro, ano 4, n. 4, p. 216-227, mar. 2003.

KAPROW, Allan. A educação do an-artista. Parte II. Concinnitas - Revista do Instituto de Artes da UERJ. Rio de Janeiro, ano 5, n. 6, p. 167-181, jul. 2004.

KAPROW, Allan. Como fazer um happening. 1966. (Tradução em português, editada para SEVERO, André). In: SEVERO, André; BERNARDES, Maria Helena (cur.). Horizonte Expandido. Santander Cultural, Porto Alegre, 2010.

PAZ, Octávio. Marcel Duchamp, ou, O castelo da pureza. São Paulo: Perspectiva, 2014.

SILVA, Ricardo Luis. Prefácio: Experiência do inútil, enfim. In: PEREC, Georges. Tentativa de esgotamento de um local parisiense. São Paulo: G. Gili, 2016. p. 7-10.

ZOURABICHVILI, François. Deleuæ̧: uma filosofia do acontecimento. Tradução de Luiz B. Orlandi. São Paulo: Editora 34, 2016.

ZOURABICHVILI, François. O vocabulário de Deleuð̌e, tradução André Telles. Rio de Janeiro: Relume Dumará: Sinergia: Ediouro, 2009. 


\section{Informações do(a) autor(a)}

Thiago Heinemann Rodeghiero

Pesquisador UFPel

E-mail:thiagoalfa@gmail.com

ORCID: https://orcid.org/0000-0001-9706-7903

Link Lattes: http://lattes.cnpq.br/ 7047575857088964

Carla Gonçalves Rodrigues

Docente PPGE/UFPel

E-mail:cgrm@ufpel.edu.br

ORCID: http://orcid.org/0000-0001-8642-8005

Link Lattes: http://lattes.cnpq.br/7498311941583904 